(2) Open Access Full Text Article

\title{
Human papillomavirus 16 infection predicts poor outcome in patients with esophageal squamous cell carcinoma
}

\author{
Ruxing $X^{\prime}$ \\ Xiaozhi Zhang' \\ Xin Chen' \\ Shupei Pan' \\ Beina Hui' \\ Li Zhang' \\ Shenbo $\mathrm{Fu}^{\prime}$ \\ Xiaolong $\mathrm{Li}^{2}$ \\ Xuanwei Zhang' \\ Tuotuo Gong' \\ Jia Guo' \\ Shaomin Che' \\ 'Department of Radiotherapy, The \\ First Affiliated Hospital of Xi'an Jiao \\ Tong University, ${ }^{2}$ Department of \\ Radiotherapy, The People's Liberation \\ Army 323 Hospital, Xi'an, People's \\ Republic of China
}

\author{
This article was published in the following Dove Press journal: \\ OncoTargets and Therapy \\ 5 March 2015 \\ Number of times this article has been viewed
}

Background: Previous studies indicate that human papillomavirus 16 (HPV16) infection plays a pivotal role in the etiology of esophageal squamous cell carcinoma (ESCC). We aim to detect the influence of HPV16 infection on ESCC patient prognosis.

Patients and methods: Immunohistochemical staining for HPV16 E6 oncoprotein, the lowaffinity p75 neurotrophin receptor (p75NTR), and phosphatidylinositol 3-kinase (PI3K) was performed on 103 archived surgical specimens from patients with ESCC and 54 control samples from patients with benign esophageal tumor or inflammatory lesions. All patients were from the Shaan Xi Province, People's Republic of China.

Results: HPV16 E6 expression was significantly higher in the ESCC group $(P<0.05)$. HPV16 E6 expression was significantly higher in men than in women $(P<0.05)$. p75NTR expression was higher in those aged $>56$ years $(P<0.05)$. PI3K expression was higher in those with a more advanced histopathological grade $(P<0.05)$. There was a positive correlation between HPV16 E6 and p75NTR expression $(r=0.547, P<0.001)$ and between $\mathrm{p} 75 \mathrm{NTR}$ and PI3K expression $(r=0.364, P<0.001)$. In 100 evaluable patients, the 5 -year overall survival (OS) rate was $11 \%$. In patients with ESCC, HPV16 E6 and PI3K expression were negatively correlated with the 3 -year OS $(P<0.05)$, 5-year OS $(P<0.05)$, and progression-free survival $(P<0.05)$.

Conclusion: HPV16 infection likely contributes to the etiology of ESCC patients in Shaan Xi, People's Republic of China. HPV16 infection status and PI3K expression levels could be useful for predicting prognosis in patients with ESCC.

Keywords: low-affinity p75 neurotrophin receptor, phosphatidylinositol 3-kinase, prognosis

\section{Introduction}

In 2011, esophageal carcinoma was the fifth and eighth most common cause of death worldwide in men and women, respectively. ${ }^{1}$ Esophageal carcinoma has a very poor survival rate, with the 5-year survival rate in developed countries ranging from $10 \%$ to $16 \% .^{2}$ On a global scale, the incidence of esophageal carcinoma is especially high in People's Republic of China, although it varies widely between provinces. Esophageal squamous cell carcinoma (ESCC) is the major histological type in Chinese populations, with a mortality rate that ranks fourth among all the cancer-related mortalities, resulting in 150,000 deaths annually. ${ }^{3}$

The etiology of ESCC has not been fully elucidated, although the involvement of Department of Radiotherapy, The First Affiliated Hospital of Xi'an Jiao Tong University, 76 YanTa West Street, Xi'an, Shaan Xi 71006I, People's Republic of China

Tel +86 I89 91232572

Fax +862985324068

Email chersm@126.com human papillomavirus (HPV) infection in esophageal carcinoma was first suggested in 1982. ${ }^{4}$ In Shaan Xi, an ESCC high-incidence region in the northwest of People's Republic of China, high-risk HPV16/18 infection has been associated with the development of ESCC. ${ }^{5}$ It was postulated that high-risk HPV was involved in the very early stage of the classical dysplasia-carcinoma sequence of ESCC because of the presence 
of HPV DNA in normal esophageal epithelium and cancer precursor lesions. $^{6}$

High-risk HPV16 E6 protein is a major oncoprotein that interferes with cell cycle regulation and enhances tumorigenesis by binding to the p53 tumor suppressor, leading to rapid p53 degradation via the ubiquitin-proteasome system. ${ }^{7}$ Therefore, the detection of HPV16 E6 oncoprotein in tissues might suggest the etiological involvement of HPV16 in ESCC.

In HPV-positive head and neck squamous cell carcinoma, the presence of a small subpopulation of cancer stem cells (CSCs) with the capacity for self-renewal has been suggested as underlying treatment-resistance. ${ }^{8} \mathrm{CSC}$ are regarded as tumor cells that maintain tumor growth and cell differentiation. Consequently, CSCs represent novel therapeutic targets because of their concentrated representation of pathological cancer characteristics. In normal human esophageal epithelial cells, a candidate stem/progenitor cell fraction was identified in vitro by the expression of the low-affinity p 75 neurotrophin receptor ( $\mathrm{p} 75 \mathrm{NTR})$. These cells have a slow cycling rate, a relatively immature phenotype, and are capable of repopulating all known epithelial cell subtypes. Therefore, expression levels of p75NTR could be considered as a candidate biomarker of CSCs in ESCC tumors. ${ }^{9,10}$

Many reports have confirmed that abnormal activation of the phosphatidylinositol 3-kinase (PI3K)/Akt signaling pathway plays a critical role in tumorigenesis of cancers including ESCC. Recently, it has been suggested that activation of the PI3K/Akt pathway is essential for the maintenance and viability of CSCs in breast cancer, prostate cancer, and brain tumors. ${ }^{11,12}$ In addition, inhibiting the PI3K/Akt pathway might result in differentiation of CSCs. ${ }^{13}$

In the present study, the expression of HPV16 E6, p75NTR, and the PI3K in postoperative tissues resected from patients with ESCC or benign esophageal tumor or normal esophageal epithelial tissues were evaluated using immunohistochemical staining (IHC). Correlation analysis of those potential markers with clinical features and prognostic 3-year, 5-year overall survival (OS) and progression-free survival (PFS) rates were performed.

\section{Materials and methods Patients and surgical specimens}

Surgical specimens, including 54 controls (benign or inflammation hyperplasia) and 103 cases (ESCC) were retrieved from patients who underwent an esophagectomy at The First Affiliated Hospital of Xi'an Jiao Tong University between September 2008 and December 2009. Patients who had received neoadjuvant treatment, who had positive resection margins (R1) according to the College of American Pathologists criteria, who had distant metastases, or those who did not reside in Shaan Xi Province were excluded from the study. The study was approved by the Ethics Committee of The First Affiliated Hospital of Xi'an Jiao Tong University, and written informed consent was obtained from all patients.

\section{Immunohistochemical staining}

Tissues were fixed in 10\% buffered formalin and embedded in paraffin then processed by standard methods. IHC was performed using an Envision system according to manufacturer's instructions. Primary antibodies included mouse monoclonal anti-HPV16 E6 (\#C1P5; Abcam, Cambridge, UK), rabbit polyclonal anti-human p75NTR (MAB367; R\&D Systems, Inc., Minneapolis, MN, USA), and rabbit polyclonal anti-human PI3K (\#4249; Cell Signaling Technology, Danvers, MA, USA). Normal epithelium was used as an internal positive control for each specimen. Negative controls were obtained by omitting the primary antibody. The proportion of positively stained cells and all tumor cells were counted over five random fields in each section, and the percentage of positively stained cells in each section was calculated. Each sample was categorized according to the area of stained cells and the intensity of staining, and the sum of the two constituted the final score. For area scoring: 0 indicated no positive staining; $1, \leq 10 \%$ of tissue stained; $2,11 \%-50 \%$ of tissue stained; $3,51 \%-75 \%$ of tissue stained; and $4,>75 \%$ of tissue stained. For intensity scoring: 0 was no staining; 1 , weak staining; 2, moderate staining; and 3, strong staining. Specimens were considered positive when the score was $\geq 4$. All slides were evaluated independently by two pathologists in a blinded fashion. For any discrepancies, a consensus was made by careful discussion between the pathologists.

\section{Follow-up visit}

All 103 patients with ESCC attended a clinic-based follow-up every 6 months for 5 years or until death. Follow-up included general health, physical and imaging examinations, biochemical testing, and a record of survival status.

\section{Statistical analyses}

The association between the protein expression levels and clinical features were evaluated using the $\chi^{2}$ test. Pearson's correlation coefficients were calculated to analyze any correlations between the expression levels of the three proteins. The Mann-Whitney $U$-test was performed to compute the differences in p75NTR and PI3K expression between HPV16 
E6-positive and HPV16 E6-negative cases. Kaplan-Meier analysis (log rank test) was used to compare the OS, which was defined as the time from the date of surgery to death, and PFS, which was defined as the time from the date of surgery to the first documented relapse of patients, between the patient groups. Cox regression analysis and the Cox proportional hazards model were applied to determine the hazard ratio (HR) of variables on 5-year OS and PFS in univariate and multivariate analysis. A two-sided $P$-value of $<0.05$ was considered statistically significant. All analyses were performed using SPSS version 19.0 for Windows.

\section{Results}

\section{Expression of HPVI6 E6, p75NTR, and $\mathrm{PI} 3 \mathrm{~K}$ in ESCC and control tissues}

The baseline characteristics of patients with ESCC and control patients are shown in Table 1. Of the 103 resected ESCC specimens, HPV16 E6, p75NTR, and PI3K expression was positive in $63.1 \%, 61.2 \%$, and $72.8 \%$, respectively (Figure 1). Of the 54 control specimens, HPV16 E6, p75NTR, and PI3K expression was positive in $22.2 \%, 20.4 \%$, and $9.3 \%$, respectively. The expression of the three proteins was significantly higher in patients with ESCC compared with controls $(P<0.05$, Table 1$)$.

\section{Correlations between protein expression levels and clinical features in patients with ESCC and correlations between the expression of HPVI6 E6, p75NTR, and PI3K}

Correlations between expression levels of HPV16 E6, p75NTR, and PI3K with clinical features such as patient age, sex, and histology are shown in Table 2. HPV16 E6 expression was higher in men compared with women $(P<0.05)$. p75NTR expression was higher in those aged $>56$ years $(P<0.05)$. Higher PI3K expression was associated with a more advanced histopathological grade $(P<0.05)$. The expression of p75NTR and PI3K was significantly different between different tumor node metastasis (TNM) stage groups of patients with ESCC $(P<0.05)$, while there was no significant difference in HPV16 E6 expression between different TNM stage groups in control patients. Meanwhile, the expression of the three proteins was not correlated with smoking status, infiltration depth, lymph nodes status, or the general classification of patients with ESCC $(P>0.05)$.

As shown in Table 2, according to the Pearson's correlations analysis, there was a positive correlation between
Table I Baseline characteristics and the expression of HPVI6 E6, P75NTR, and PI3K in ESCC patients and controls

\begin{tabular}{|c|c|c|}
\hline Characteristics & $\begin{array}{l}\text { ESCC patients } \\
\mathrm{N}=103\end{array}$ & $\begin{array}{l}\text { Controls } \\
\mathrm{N}=54\end{array}$ \\
\hline \multicolumn{3}{|l|}{ Age } \\
\hline Median (range) & $56(38-74)$ & $48(22-76)$ \\
\hline \multicolumn{3}{|l|}{ Sex } \\
\hline Male & 84 & 30 \\
\hline Female & 19 & 24 \\
\hline \multicolumn{3}{|l|}{ Smoking status* } \\
\hline Yes & 71 & 26 \\
\hline No & 32 & 28 \\
\hline \multicolumn{3}{|l|}{ Tumor differentiation } \\
\hline GI & 7 & NE \\
\hline G2 & 78 & NE \\
\hline G3 & 18 & NE \\
\hline \multicolumn{3}{|l|}{ Infiltration depth } \\
\hline Submucosa & 10 & NE \\
\hline Superficial myoinvasion & 11 & NE \\
\hline Deep myoinvasion & 14 & NE \\
\hline Full thickness & 68 & NE \\
\hline \multicolumn{3}{|l|}{ Lymph node status } \\
\hline Negative & 51 & NE \\
\hline Positive & 52 & NE \\
\hline \multicolumn{3}{|l|}{ General classification } \\
\hline Ulcerative type & 45 & NE \\
\hline Medullary type & 42 & NE \\
\hline Fungating type & 15 & NE \\
\hline Constrictive type & I & NE \\
\hline \multicolumn{3}{|l|}{ TNM staging } \\
\hline I & 7 & NE \\
\hline ॥ & 58 & NE \\
\hline III & 35 & NE \\
\hline IV & 3 & NE \\
\hline \multicolumn{3}{|l|}{ HPVI6 } \\
\hline Negative & 38 & 42 \\
\hline Positive & 65 & 12 \\
\hline$P$ & $<0.001$ & \\
\hline \multicolumn{3}{|l|}{ p75NTR } \\
\hline Negative & 40 & 43 \\
\hline Positive & 63 & 11 \\
\hline$P$ & $<0.00 \mathrm{I}$ & \\
\hline \multicolumn{3}{|l|}{ PI3K } \\
\hline Negative & 28 & 49 \\
\hline Positive & 75 & 5 \\
\hline$P$ & $<0.001$ & \\
\hline
\end{tabular}

Note: *The equivalent of smoking one pack of cigarettes per day for I year was defined as smoking status positive.

Abbreviations: ESCC, esophageal squamous cell carcinoma; HPVI6, human papillomavirus 16; PI3K, phosphatidylinositol 3-kinase; p75NTR, low-affinity p75 neurotrophin receptor; NE, not estimable;TNM, tumor node metastasis.

HPV16 E6 and p75NTR expression level in ESCC tumors $(r=0.547, P<0.001)$. There was also a positive correlation between $\mathrm{p} 75 \mathrm{NTR}$ and PI3K expression in ESCC tumors ( $r=0.364, P<0.001)$. However, there was no significant correlation between PI3K and HPV16 E6 expression $(r=0.166, P>0.05)$. 

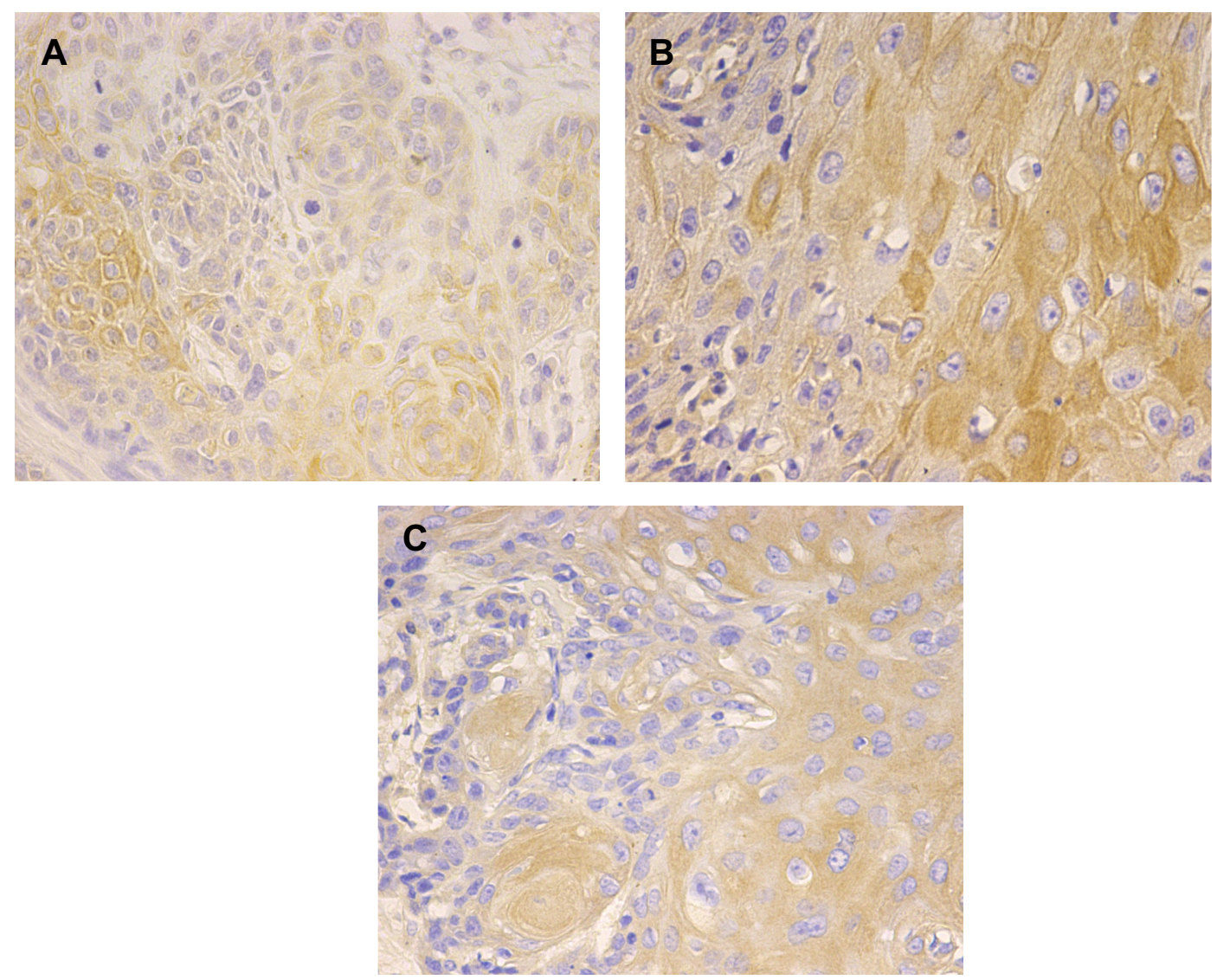

Figure I The expression of HPVI6 E6, p75NTR, and PI3K in ESCC tissues detected by immunohistochemical staining.

Notes: HPVI6 E6 protein (A) is expressed mainly in the nucleus and cytoplasm of esophageal squamous cell carcinoma (ESCC) patients and controls; p75NTR (B) and PI3K (C) proteins are expressed mainly in the cytoplasm and membrane of ESCCs and controls.

Abbreviations: HPVI6, human papillomavirus 16; PI3K, phosphatidylinositol 3-kinase; p75NTR, low-affinity p75 neurotrophin receptor.

\section{Survival analysis and prognostic value of HPVI6 E6, p75NTR, and PI3K expression in patients with ESCC}

The follow-up rate, which was defined as the number of patients without loss to follow-up as a proportion of the total number of patients recruited, was $97.1 \%(100 / 103)$. The follow-up ended on September 25, 2014, with a mean follow-up of 32.64 months (range 7-67 months), and the estimated 5-year OS was $11 \%(11 / 100)$. According to the Kaplan-Meier analysis, age $>56$ years, male sex, an advanced TNM stage, a general classification of medullary type ESCC, and no postoperative adjunctive treatment were significantly associated with poor OS and PFS $(P<0.05$, Table 3). Smoking status, tumor differentiation, and lymph node status were not correlated with the OS or PFS $(P>0.05$, Table 3). However, the infiltration depth was correlated with OS but not with PFS $(P<0.05, P>0.05$, respectively, Table 3).

Furthermore, as shown in Table 4 and Figure 2, multivariate analysis revealed that HPV16 E6-positive or
PI3K-positive patients had significantly worse 5-year OS compared with HPV16 E6-negative or PI3K-negative patients (HR $=1.874, P=0.021 ; \mathrm{HR}=1.961, P=0.011$, respectively). These patients also had a significantly worse PFS (HR $=1.740$, $P=0.04 ; \mathrm{HR}=2.077, P=0.006$, respectively). The TNM stage was also an independent factor of poor prognosis for 5-year OS (HR $=1.506, P=0.03)$, but not the PFS (HR $=1.410, P>0.05)$. No significant correlations were found between the expression of p75NTR and 5-year OS or PFS $(P>0.05)$ or postsurgical treatment and 5-year OS or PFS $(P>0.05)$.

The 3-year OS was also taken into consideration, as shown in Table 4 and Figure 2; HPV16 E6-positive patients with ESCC had significantly worse 3-year OS compared with HPV16 E6-negative patients with ESCC (HR =2.118, $P<0.05)$. In addition, PI3K-positive patients with ESCC had significantly worse 3-year OS compared with PI3K-negative patients with $\mathrm{ESCC}(\mathrm{HR}=1.896, P<0.05)$. There were no significant differences in 3-year OS based on p75NTR expression $(\mathrm{HR}=1.247, P>0.05)$. 
Table 2 Correlations between the expression of HPVI6 E6, p75NTR, PI3K, and clinical features in ESCC patients

\begin{tabular}{|c|c|c|c|c|c|c|}
\hline & \multicolumn{2}{|l|}{ HPVI6 } & \multicolumn{2}{|l|}{ p75NTR } & \multicolumn{2}{|l|}{ PI3K } \\
\hline & Negative & Positive & Negative & Positive & Negative & Positive \\
\hline \multicolumn{7}{|l|}{ Median age } \\
\hline$\leq 56$ years & 18 & 38 & 22 & 34 & 21 & 35 \\
\hline$>56$ years & 20 & 27 & 18 & 29 & 7 & 40 \\
\hline$P$ & 0.275 & & 0.918 & & 0.010 & \\
\hline \multicolumn{7}{|l|}{ Sex } \\
\hline Male & 26 & 58 & 31 & 53 & 23 & 61 \\
\hline Female & 12 & 7 & 9 & 10 & 5 & 14 \\
\hline$P$ & 0.009 & & 0.398 & & 0.925 & \\
\hline \multicolumn{7}{|l|}{ Smoking status } \\
\hline Yes & 24 & 47 & 25 & 46 & 20 & 51 \\
\hline No & 14 & 18 & 15 & 17 & 8 & 24 \\
\hline$P$ & 0.333 & & 0.261 & & 0.738 & \\
\hline \multicolumn{7}{|l|}{ Tumor differentiation } \\
\hline GI & 0 & 7 & I & 6 & 1 & 7 \\
\hline G2 & 29 & 49 & 37 & 41 & 23 & 55 \\
\hline G3 & 9 & 9 & 2 & 16 & 5 & 13 \\
\hline$P$ & 0.066 & & 0.007 & & 0.243 & \\
\hline \multicolumn{7}{|l|}{ Infiltration depth } \\
\hline Submucosa & 4 & 6 & 2 & 8 & 4 & 6 \\
\hline Superficial myoinvasion & 3 & 8 & 3 & 8 & 0 & 11 \\
\hline Deep myoinvasion & 7 & 7 & 5 & 9 & 5 & 9 \\
\hline Full thickness & 24 & 44 & 30 & 38 & 19 & 49 \\
\hline$P$ & 0.662 & & 0.396 & & 0.140 & \\
\hline \multicolumn{7}{|l|}{ Lymph node status } \\
\hline Negative & 18 & 33 & 18 & 33 & 11 & 40 \\
\hline Positive & 20 & 32 & 22 & 30 & 17 & 35 \\
\hline$P$ & 0.739 & & 0.465 & & 0.205 & \\
\hline \multicolumn{7}{|l|}{ TNM staging } \\
\hline 1 & 2 & 5 & 2 & 5 & 4 & 3 \\
\hline II & 22 & 36 & 16 & 42 & 7 & 51 \\
\hline III & 14 & 21 & 19 & 16 & 17 & 18 \\
\hline IV & 0 & 3 & 3 & 0 & 0 & 3 \\
\hline$P$ & 0.545 & & 0.009 & & 0.000 & \\
\hline \multicolumn{7}{|l|}{ General classification } \\
\hline Ulcerative type & 17 & 28 & 20 & 25 & 17 & 28 \\
\hline Medullary type & 17 & 25 & 18 & 24 & 9 & 33 \\
\hline Constrictive type & 0 & 1 & 0 & 1 & I & 0 \\
\hline Fungating type & 4 & 11 & 2 & 13 & 2 & 13 \\
\hline$P$ & 0.634 & & 0.084 & & 0.097 & \\
\hline \multicolumn{7}{|l|}{ HPVI6 } \\
\hline Negative & - & - & 28 & 10 & 14 & 24 \\
\hline Positive & - & - & 12 & 53 & 14 & 51 \\
\hline$r$ and $P$ & & & $r=0.547, P<$ & & $r=0.364, P<$ & \\
\hline \multicolumn{7}{|l|}{ p75NTR } \\
\hline Negative & - & - & - & - & 19 & 21 \\
\hline Positive & - & - & - & - & 9 & 54 \\
\hline$r$ and $P$ & & & & & $r=0.166, P>$ & \\
\hline
\end{tabular}

Abbreviations: ESCC, esophageal squamous cell carcinoma; HPVI6, human papillomavirus 16; PI3K, phosphatidylinositol 3-kinase; p75NTR, low-affinity p75 neurotrophin receptor; TNM, tumor node metastasis.

\section{Discussion}

The prevalence of HPV infection in esophageal premalignant lesions or carcinoma varies $(0 \%-88 \%)$ in different populations and from study to study. ${ }^{14}$ Variations in sampling methods, demographic and ethnic factors, anatomic sites, and methods used for viral detection have all been suggested as potential causes of these discrepancies. IHC measures of HPV activity in cervical and head and neck cancer were used to analyze the expression of the surrogate marker p $16^{\mathrm{INK} 4 \mathrm{a}} \cdot{ }^{15}$ Consequently, detection of the HPV16 oncoprotein E6 was 
Table 3 Kaplan-Meier analysis of clinical features in ESCC patients

\begin{tabular}{|c|c|c|c|c|}
\hline & $\begin{array}{l}\text { Median OS } \\
\text { (months) }\end{array}$ & $P$ & $\begin{array}{l}\text { Median PFS } \\
\text { (months) }\end{array}$ & $P$ \\
\hline \multicolumn{5}{|l|}{ Age } \\
\hline$\leq 56$ years & 31 & & 31 & \\
\hline$>56$ years & 23 & 0.023 & 18 & 0.017 \\
\hline \multicolumn{5}{|l|}{ Sex } \\
\hline Male & 21 & & 18 & \\
\hline Female & 51 & 0.000 & 48 & 0.001 \\
\hline \multicolumn{5}{|l|}{ Smoking status } \\
\hline Yes & 23 & & 19 & \\
\hline No & 36 & 0.263 & 30 & 0.294 \\
\hline \multicolumn{5}{|l|}{ Tumor differentiation } \\
\hline GI & 22 & & 13 & \\
\hline $\mathrm{G} 2$ & 31 & & 28 & \\
\hline G3 & 18 & 0.369 & 18 & 0.289 \\
\hline \multicolumn{5}{|l|}{ Infiltration depth } \\
\hline Submucosa & 31 & & 31 & \\
\hline Superficial myoinvasion & 26 & & 25 & \\
\hline Deep myoinvasion & 48 & & 41 & \\
\hline Full thickness & 20 & 0.044 & 18 & 0.063 \\
\hline \multicolumn{5}{|l|}{ Lymph node status } \\
\hline Negative & 37 & & 30 & \\
\hline Positive & 18 & 0.316 & 18 & 0.532 \\
\hline \multicolumn{5}{|l|}{ General classification } \\
\hline Ulcerative type & 31 & & 30 & \\
\hline Medullary type & 19 & & 18 & \\
\hline Fungating type & 48 & 0.009 & 31 & 0.008 \\
\hline \multicolumn{5}{|l|}{ Treatment } \\
\hline Surgery alone & 18 & & 18 & \\
\hline Surgery + chemotherapy & 36 & & 31 & \\
\hline Surgery + radiotherapy & 37 & & 36 & \\
\hline Surgery + chemotherapy + radiotherapy & 18 & 0.007 & 18 & 0.014 \\
\hline \multicolumn{5}{|l|}{ TNM staging } \\
\hline I & 51 & & 51 & \\
\hline ॥ & 31 & & 28 & \\
\hline III & 18 & & 18 & \\
\hline IV & 14 & 0.003 & 14 & 0.001 \\
\hline
\end{tabular}

Abbreviations: ESCC, esophageal squamous cell carcinoma; OS, overall survival; PFS, progression-free survival; TNM, tumor node metastasis.

utilized as a surrogate marker in the current study to detect HPV infection.

Here, the incidence of HPV16 E6-positivity was significantly higher in patients with ESCC compared with controls, suggesting that, in Shaan Xi Province, the prevalence of
HPV16 among patients with ESCC is considerably high, and that high-risk HPV infection may be a carcinogenic factor underlying the etiology of ESCC. These results are concordant with those of other studies. For example, a study in a population in Anyang, People's Republic of China revealed

Table 4 Multivariate COX analysis for 3-year OS, 5-year OS, and PFS in ESCC patients

\begin{tabular}{|c|c|c|c|c|c|c|c|c|c|}
\hline & \multicolumn{3}{|l|}{ 5-year OS } & \multicolumn{3}{|l|}{ PFS } & \multicolumn{3}{|l|}{ 3-year OS } \\
\hline & $95 \% \mathrm{Cl}$ & HR & $P$-value & $95 \% \mathrm{Cl}$ & HR & $P$-value & $95 \% \mathrm{Cl}$ & HR & $P$-value \\
\hline TNM staging & $1.04-2.180$ & 1.506 & 0.030 & $0.983-2.023$ & 1.410 & 0.062 & - & - & - \\
\hline Treatment & $0.593-1.129$ & 0.818 & 0.223 & $0.613-1.147$ & 0.838 & 0.271 & - & - & - \\
\hline HPVI6 & $1.098-3.197$ & 1.874 & 0.021 & $1.025-2.954$ & 1.740 & 0.040 & $1.255-3.574$ & 2.118 & 0.005 \\
\hline p75NTR & $0.44 I-1.299$ & 0.757 & 0.312 & $0.455-1.338$ & 0.780 & 0.368 & $0.7388-2.105$ & 1.247 & 0.408 \\
\hline PI3K & $1.166-3.299$ & 1.961 & 0.011 & $1.240-3.479$ & 2.077 & 0.006 & $1.083-3.318$ & 1.896 & 0.025 \\
\hline
\end{tabular}

Abbreviations: $\mathrm{Cl}$, confidence interval; ESCC, esophageal squamous cell carcinoma; HPVI6, human papillomavirus I6; HR, hazard ratio; OS, overall survival; PI3K, phosphatidylinositol 3-kinase; p75NTR, low-affinity p75 neurotrophin receptor; PFS, progression-free survival; TNM, tumor node metastasis. 
A

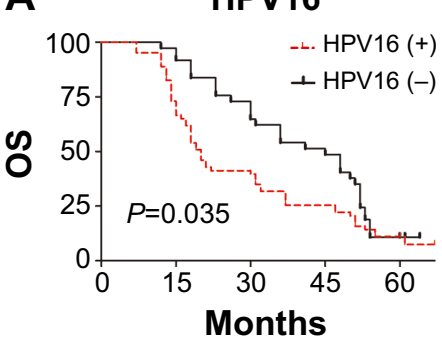

B

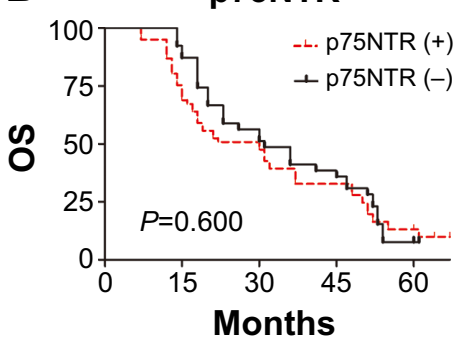

C

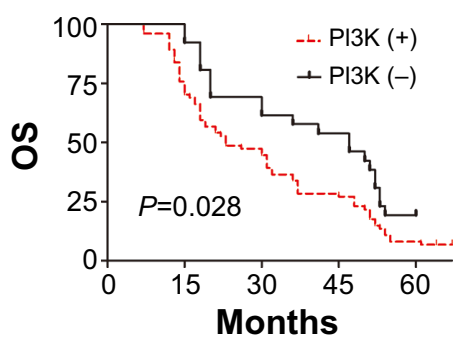

D

HPV16

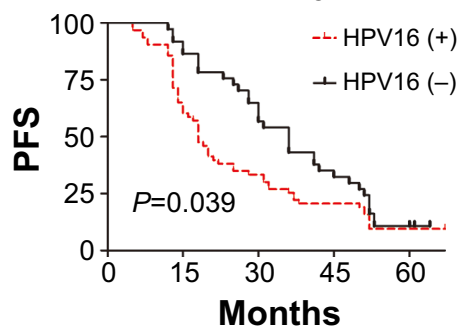

$\mathbf{E}$

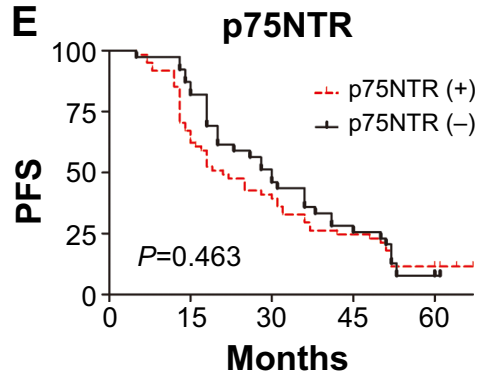

$\mathbf{F}$

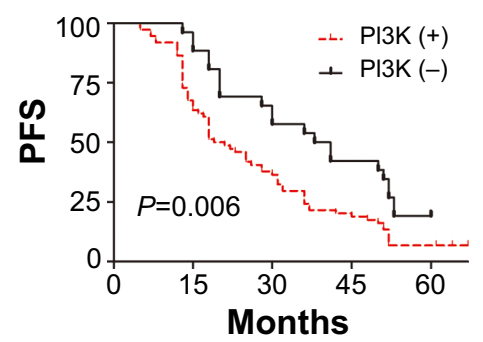

HPV16

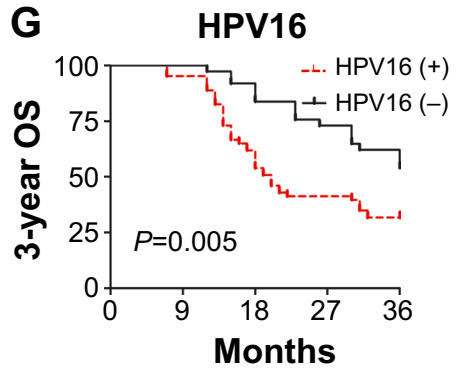

H P75NTR
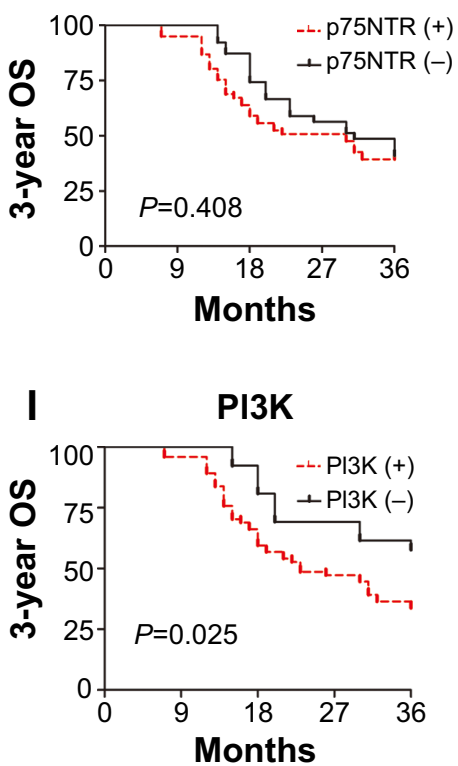

Figure 2 Survival curves of 3-year OS, OS, and PFS of ESCC patients according to HPVI6, P75NTR, and PI3K expression.

Notes: Kaplan-Meier estimates of survival among esophageal squamous cell carcinoma (ESCC) patients, according to the tumor human papillomavirus I6 (HPVI6) status or p75 neurotrophin receptor (P75NTR)-expression status or phosphatidylinositol 3-kinase (PI3K)-expression status; For the 5-year overall survival (OS) rate (A) and progression-free survival (PFS) rate (D), HPVI6 positive is significantly associated with poor prognosis $(P=0.021, P=0.04$, respectively); For the 5 -year OS rate (B) and PFS rate $(E)$, there is no relationship between $p 75 N T R$ expression and prognosis $(P=0.312, P=0.368$, respectively); For the 5 -year OS rate $(\mathbf{C})$ and $P F S$ rate $(\mathbf{F})$, $P I 3 K$ positive is significantly associated with poor prognosis $(P=0.011, P=0.006$, respectively); Consistently, for the 3-year OS rate, HPVI6 and $P I 3 K$ positive (G, H, respectively) are significantly correlated with poor prognosis $(P=0.005, P=0.025$, respectively) while there is still no association between $p 75 N T R$ and prognosis $(I, P=0.408)$.

that HPV16 E7 antibody was detected at a significantly higher level in patients with ESCC, compared with control patients. ${ }^{16}$ Moreover, HPV DNA detection was as high as $65 \%$ in Gansu, which has one of the highest incidences of ESCC in People's Republic of China. ${ }^{17}$

In patients with HPV16/18-positive cervical cancer, E6/E7 oncogene expression was independently associated with a poor prognosis. ${ }^{18}$ In addition, the 5-year survival rate of HPV DNA-positive patients with vulvar squamous cell carcinoma was lower than that of HPV-negative patients. ${ }^{19}$ However, whether or not HPV16 infection status could serve as an independent prognostic marker in patients with ESCC has been debatable. A pilot study detected HPV16 in patients with ESCC alone, but HPV16 infection status did not significantly affect survival, although the authors suggested that the limited sample size might have contributed to the lack of effect on survival. However, in patients with ESCC, compared with HPV-negative patients, HPV-positive patients who received preoperative neoadjuvant chemotherapy or radiotherapy had improved treatment responses and prognosis. ${ }^{20}$ Here, in patients with ESCC, the 3- and 5-year OS and PFS rates of HPV16-negative patients were significantly better than those of HPV16-positive patients, inferring that HPV16 infection may be an unfavorable prognostic factor in patients with ESCC.

Expression of the high-risk HPV16 E6/E7 oncogene can lead to malignant transformation in various cell lines, and a recent study indicated that stem cells might participate in this process. ${ }^{21}$ Stem cells are enriched in basal cells of the normal esophageal epithelium. The $\alpha 6 \beta 1$ and $\alpha 6 \beta 4$ integrins are not only biomarkers of normal esophageal epithelial stem and progenitor cells, but they also mediate the invasion of 
HPV16 E6/E7 oncogene into cells. ${ }^{22}$ This suggests that the HPV16 E6/E7 oncogene might possibly target the stem or progenitor cells of normal esophageal epithelium to induce carcinogenesis, although further studies are needed to uncover the mechanisms underlying the carcinogenic action of the HPV16 E6/E7 oncogene in these cells.

As a member of tumor necrosis factor receptor family, p75NTR is expressed in the progenitor cells of human esophageal keratinocytes and is a marker of esophageal CSCs. ${ }^{23,24}$ In a previous study, we demonstrated that the proportion of p75NTR-positive cells increased dramatically in CSC-like radiation-resistant Eca109R-50Gy cells, which was achieved in response to 50 Gy irradiation. ${ }^{25,26}$ In the present study, p75NTR expression was significantly higher in patients with ESCC compared with controls, and the expression tended to increase with advancing tumor stage. There was also a significant positive correlation between the expression of HPV16 E6 and p75NTR, suggesting that both HPV16 infection and CSC activation may participate in ESCC progression although their potential relationship requires further investigation. However, the p75NTR expression level was not correlated with the clinical prognosis when known prognostic variables such as the TNM stage and treatment after surgery were excluded. To confirm the role of $\mathrm{p} 75 \mathrm{NTR}$ as a positive prognostic marker in patients with ESCC, future prospective studies enrolling more patients are needed.

Activation of the PI3K/Akt signaling pathway has been implicated in human cancers including esophageal cancer. LY294002, a specific PI3K inhibitor, causes prominent cell differentiation in human embryonic stem cells. ${ }^{27}$ In radioresistant ESCC cells that have CSC-like properties, Akt mRNA and protein levels increased in response to irradiation, suggesting that the PI3K/Akt pathway was activated. ${ }^{25,26}$ The PI3K/Akt pathway was also important in maintaining pluripotency of mouse embryonic stem cells. ${ }^{28}$ Gupta et $\mathrm{al}^{29}$ found that the radiosensitivities of HPV-positive human head and neck squamous cell carcinoma UPCI-SCC90 and UMSCC47 cell lines were higher than that of the HPVnegative cell line SQ20B because of PI3K/Akt pathway activation. In xenografted mice bearing human gliomas, inhibition of Akt activity in CSCs resulted in sensitization of cells to treatment and promoted survival. ${ }^{11,12,30}$

In concordance with previous research, PI3K expression was significantly higher in patients with ESCC compared with controls. The higher PI3K expression level was correlated with an advanced TNM stage and a poor prognosis, but there was no significant correlation between the expression of PI3K and HPV16 E6. This indicates that invasion of the HPV16 oncogene into esophageal cells and the carcinogenic process may not involve PI3K/Akt pathway activation. Further evaluation of the molecular mechanisms underlying the interaction of HPV16 E6 and PI3K/Akt signaling is required.

\section{Conclusion}

High-risk HPV infection, especially HPV16, has a high prevalence, and it might play an important role in the etiology of ESCC. HPV16 infection or high PI3K expression in patients with ESCC were independently associated with poor OS and PFS, whereas p75NTR expression was not correlated with clinical prognosis.

\section{Acknowledgments}

This study was supported by the National Natural Science Foundation of China (81201922) and Science and Technology Research Projects of Shaan Xi Province (2012K13-02-33).

We would like to thank the staff in the Departments of Pathology and Radiotherapy in the First Affiliated Hospital of Xi'an Jiao Tong University for their help and support.

\section{Disclosure}

All authors are in agreement with the content of the manuscript. The authors report no conflicts of interest in this work.

\section{References}

1. Jemal A, Bray F, Center MM, Ferlay J, Ward E, Forman D. Global cancer statistics. CA Cancer J Clin. 2011;61(2):69-90.

2. Sant M, Allemani C, Santaquilani M, Knijn A, Marchesi F, Capocaccia R; EUROCARE Working Group. EUROCARE-4. Survival of cancer patients diagnosed in 1995-1999. Results and commentary. Eur J Cancer. 2009;45(6):931-991.

3. Zhao P, Dai M, Chen W, Li N. Cancer trends in China. Jpn J Clin Oncol. 2010;40(4):281-285.

4. Syrjänen K, Syrjänen S, Pyrhönen S. Human papilloma virus (HPV) antigens in lesions of laryngeal squamous cell carcinomas. $O R L$ J Otorhinolaryngol Relat Spec. 1982;44(6):323-334.

5. Guo F, Liu Y, Wang X, et al. Human papillomavirus infection and esophageal squamous cell carcinoma: a case-control study. Cancer Epidemiol Biomarkers Prev. 2012;21(5):780-785.

6. Astori G, Merluzzi S, Arzese A, et al. Detection of human papillomavirus DNA and p53 gene mutations in esophageal cancer samples and adjacent normal mucosa. Digestion. 2001;64(1):9-14.

7. Scheffner M, Werness BA, Huibregtse JM, Levine AJ, Howley PM. The E6 oncoprotein encoded by human papillomavirus types 16 and 18 promotes the degradation of p53. Cell. 1990;63(6):1129-1136.

8. de Jong MC, Pramana J, van der Wal JE, et al. CD44 expression predicts local recurrence after radiotherapy in larynx cancer. Clin Cancer Res. 2010;16(21):5329-5338.

9. Okumura T, Tsunoda S, Mori Y, et al. The biological role of the low-affinity p75 neurotrophin receptor in esophageal squamous cell carcinoma. Clin Cancer Res. 2006;12(17):5096-5103.

10. Davidson B, Reich R, Lazarovici P, Ann Flørenes V, Nielsen S, Nesland JM. Altered expression and activation of the nerve growth factor receptors TrkA and p75 provide the first evidence of tumor progression to effusion in breast carcinoma. Breast Cancer Res Treat. 2004;83(2):119-128. 
11. Dubrovska A, Kim S, Salamone RJ, et al. The role of PTEN/Akt/PI3K signaling in the maintenance and viability of prostate cancer stem-like cell populations. Proc Natl Acad Sci U S A. 2009;106(1):268-273.

12. Hambardzumyan D, Becher OJ, Rosenblum MK, Pandolfi PP, Manova-Todorova K, Holland EC. PI3K pathway regulates survival of cancer stem cells residing in the perivascular niche following radiation in medulloblastoma in vivo. Genes Dev. 2008;22(4):436-448.

13. Massard C, Deutsch E, Soria JC. Tumour stem cell-targeted treatment: elimination or differentiation. Ann Oncol. 2006;17(11):1620-1624.

14. Syrjänen KJ. HPV infections and oesophageal cancer. J Clin Pathol. 2002;55(10):721-728.

15. Löfdahl HE, Du J, Näsman A, et al. Prevalence of human papillomavirus (HPV) in oesophageal squamous cell carcinoma in relation to anatomical site of the tumour. PLoS One. 2012;7(10):e46538.

16. He Z, Xu Z, Hang D, et al. Anti-HPV-E7 seropositivity and risk of esophageal squamous cell carcinoma in a high-risk population in China. Carcinogenesis. 2014;35(4):816-821.

17. Shuyama K, Castillo A, Aguayo F, et al. Human papillomavirus in high- and low-risk areas of oesophageal squamous cell carcinoma in China. Br J Cancer. 2007;96(10):1554-1559.

18. de Boer MA, Jordanova ES, Kenter GG, et al. High human papillomavirus oncogene mRNA expression and not viral DNA load is associated with poor prognosis in cervical cancer patients. Clin Cancer Res. 2007; 13(1):132-138.

19. Knopp S, Nesland JM, Tropé C, Holm R. p14ARF, a prognostic predictor in HPV-negative vulvar carcinoma. Am J Clin Pathol. 2006;126(2): 266-276.

20. Bognar G, Imdahl A, Ledniczky G, Ondrejka P. Possible role of human papilloma virus infection in response to neoadjuvant therapy in patients with esophageal cancer. Hepatogastroenterology. 2008;55(81): 93-97.

21. Piltti K, Kerosuo L, Hakanen J, et al. E6/E7 oncogenes increase and tumor suppressors decrease the proportion of self-renewing neural progenitor cells. Oncogene. 2006;25(35):4880-4889.
22. Croagh D, Phillips WA, Redvers R, Thomas RJ, Kaur P. Identification of candidate murine esophageal stem cells using a combination of cell kinetic studies and cell surface markers. Stem Cells. 2007;25(2): 313-318.

23. Dollé L, El Yazidi-Belkoura I, Adriaenssens E, Nurcombe V, Hondermarck H. Nerve growth factor overexpression and autocrine loop in breast cancer cells. Oncogene. 2003;22(36):5592-5601.

24. Okumura T, Shimada Y, Imamura M, Yasumoto S. Neurotrophin receptor p75(NTR) characterizes human esophageal keratinocyte stem cells in vitro. Oncogene. 2003;22(26):4017-4026.

25. Che SM, Zhang XZ, Hou L, Song TB. Cyclooxygenase-2 inhibitor NS398 enhances radiosensitivity of radioresistant esophageal cancer cells by inhibiting AKT activation and inducing apoptosis. Cancer Invest. 2010;28(7):679-688.

26. Che SM, Zhang XZ, Liu XL, Chen X, Hou L. The radiosensitization effect of NS398 on esophageal cancer stem cell-like radioresistant cells Dis Esophagus. 2011;24(4):265-273.

27. Armstrong L, Hughes O, Yung S, et al. The role of PI3K/AKT, MAPK/ ERK and NFkappabeta signalling in the maintenance of human embryonic stem cell pluripotency and viability highlighted by transcriptional profiling and functional analysis. Hum Mol Genet. 2006;15(11): 1894-1913.

28. Imai Y, Yamagishi H, Ono Y, Ueda Y. Versatile inhibitory effects of the flavonoid-derived PI3K/Akt inhibitor, LY294002, on ATP-binding cassette transporters that characterize stem cells. Clin Transl Med. 2012; $1(1): 24$.

29. Gupta AK, Lee JH, Wilke WW, et al. Radiation response in two HPV-infected head-and-neck cancer cell lines in comparison to a nonHPV-infected cell line and relationship to signaling through AKT. Int J Radiat Oncol Biol Phys. 2009;74(3):928-933.

30. Eyler CE, Foo WC, LaFiura KM, McLendon RE, Hjelmeland AB, Rich JN. Brain cancer stem cells display preferential sensitivity to Akt inhibition. Stem Cells. 2008;26(12):3027-3036.
OncoTargets and Therapy

\section{Publish your work in this journal}

OncoTargets and Therapy is an international, peer-reviewed, open access journal focusing on the pathological basis of all cancers, potential targets for therapy and treatment protocols employed to improve the management of cancer patients. The journal also focuses on the impact of management programs and new therapeutic agents and protocols on

\section{Dovepress}

patient perspectives such as quality of life, adherence and satisfaction. The manuscript management system is completely online and includes a very quick and fair peer-review system, which is all easy to use. Visit http://www.dovepress.com/testimonials.php to read real quotes from published authors. 